\title{
EXTENSIBILITY OF STRIPS OF SCLERA AND CORNEA*
}

\author{
BY
}

\author{
J. GLOSTER, E. S. PERKINS, AND MARIE-LOUISE POMMIER $\dagger$
}

Institute of Ophthalmology, University of London

THE relationship between changes of volume and changes of pressure in the eye is of considerable importance in the theory and practical application of tonometry and tonography. On the basis of the experimental evidence of earlier workers, Friedenwald (1937) claimed that this relationship could be expressed by the equation:

$$
\log \frac{P}{P_{o}}=K \Delta V,
$$

Where $P_{o}=$ Initial pressure

$P=$ Pressure after a change in intra-ocular volume $\Delta V$

$K=$ a coefficient of ocular rigidity.

Friedenwald stated that the value of $K$ remained constant for individual eyes above a pressure of $5 \mathrm{~mm}$. $\mathrm{Hg}$.

In a recent study (Perkins and Gloster, 1957), however, it has been found that for the rabbit eye this fundamental assumption is invalid, for $K$ increased as the pressure at which it was determined increased (Fig. 1, overleaf). Indeed, we were unable to formulate a simple expression for the relationship between changes in volume and changes in pressure in the eye of this animal, and suggested that a study of the extensibility of the sclera and cornea might help to explain our observations.

Little work appears in the literature on this problem. Schelske (1864) gave figures for a coefficient of elasticity for the cornea and sclera of human and rabbit eyes. In human eyes he found that there was a small difference (approximately 7 per cent.) between the coefficient for meridional and equatorial strips of sclera, but that the cornea was more than twice as extensible as the sclera. In the rabbit the cornea was found to be only some 20 per cent. more extensible than equatorial strips of sclera. Weber (1877) found a large variation in the extensibility of strips of sclera from different human eyes, but gave no figures for the cornea.

Ischreyt (1899), using cattle sclera, measured the weight required to break strips of sclera, the extension of the strips at the moment of breaking, and the extension produced by increasing weights. The weights used, however, produced tensions in the sclera corresponding to intra-ocular pressures far above physiological levels.

* Received for publication November 15, 1956

+ British Council Scholar. 


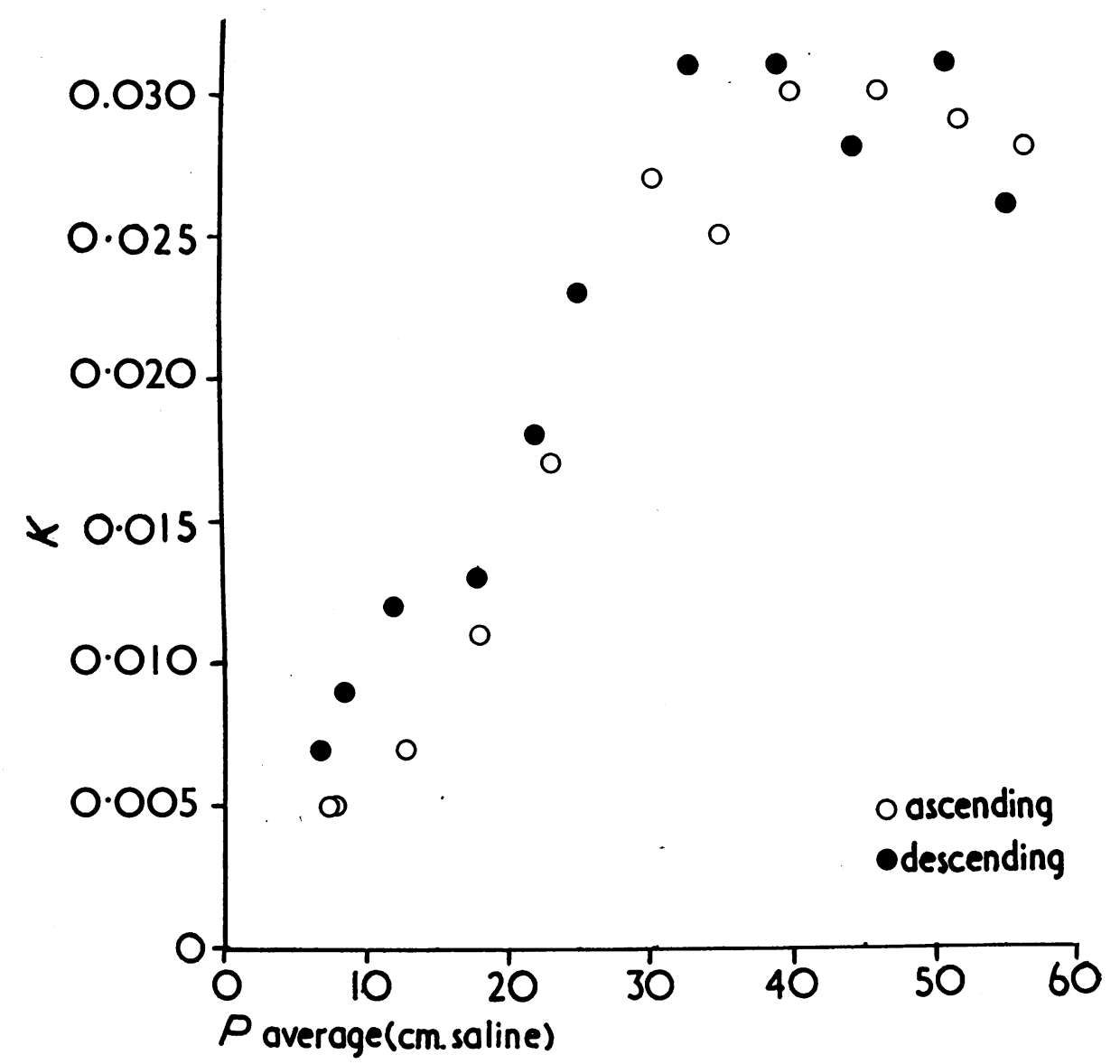

Fig. 1.-Variation of coefficient of rigidity $K$ with intra-ocular pressure for a rabbit eye.

We have measured the extensibility of strips of sclera and cornea, using weights which produced tensions more nearly resembling those in the sclera of the normal eye.

\section{Method}

The principle of the method employed consisted in suspending strips of cornea or sclera from one arm of a balance with the lower end of the strip fixed. Weights were added to the opposite scale pan and the extension of the strip was measured by the excursion of the pointer attached to the beam.

The strips were cut from enucleated rabbit eyes by means of two razor blades clamped together with their edges $1 \mathrm{~mm}$. apart. Except at the extremities where the strips were made wider to provide a larger surface area for clamping, the strips were $1 \mathrm{~mm}$. wide. Both equatorial and meridional strips from the sclera were studied.

The strips were held by small perspex clamps, the upper one being suspended 
from one arm of the balance while the lower clamp was fixed to a metal rod held vertically on a heavy platform standing over the balance pan (Fig. 2). The height of the rod could be adjusted and the rod could be clamped to the platform, thus forming a secure anchor for the lower end of the strip. A perspex chamber filled with saline surrounded the strip to prevent dehydration.

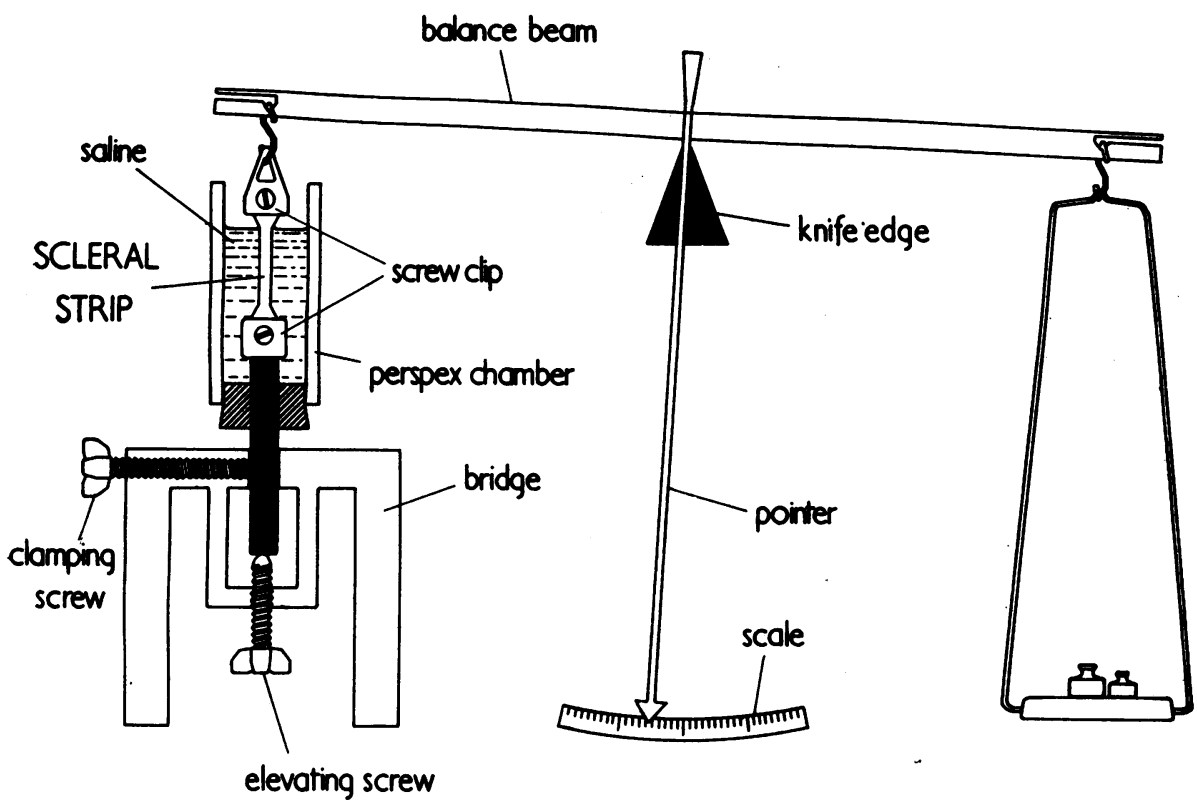

Fig. 2.-Diagram of apparatus for determining extensibility of strips of sclera and cornea.

The lower clamp attached to the metal rod was first raised until the whole weight of the strip was taken by the upper clamp. The upper clamp and strip of sclera were counterbalanced by adding weights to the right-hand scale-pan; the metal rod was then lowered until the sclera was straightened but not under tension. A $500 \mathrm{mg}$. weight was then added to the right-hand scale-pan and the movement of the pointer $P$ was measured at frequent time intervals until a steady reading was obtained. Further $500-\mathrm{mg}$. weights were added until a total of either 3 or $6 \mathrm{~g}$. was reached. The weights were then removed successively and a series of readings taken as before.

The pointer of the balance was fitted with an optical magnifying system allowing accurate reading to one division on the scale. Calibration by means of a micrometer attached to the point of suspension of the strip showed that a movement of the pointer of one division corresponded to a change in length of $0.015 \mathrm{~mm}$.

It can be shown that the tension $T$ in the strip expressed in $\mathrm{g} . \mathrm{wt} / \mathrm{cm}$. is given by the formula:

$$
T=10 \times\left(\mathrm{W}-S_{o}+S\right)
$$

where $S_{o}=$ Initial scale reading,

$S=$ Scale reading after adding weight,

$W=$ Weight added in grammes. 


\section{Results}

The first property of the strips of sclera and cornea which was noticed was the relatively long interval required for a steady state to be reached after the addition or removal of each weight. The greater part of the change in length took place in the first 15 seconds after the addition or removal of the weight, but the change was not completed until periods of up to 6 minutes had elapsed and the strip never returned to its original length after removal of the weights. Fig. 3 illustrates these effects.

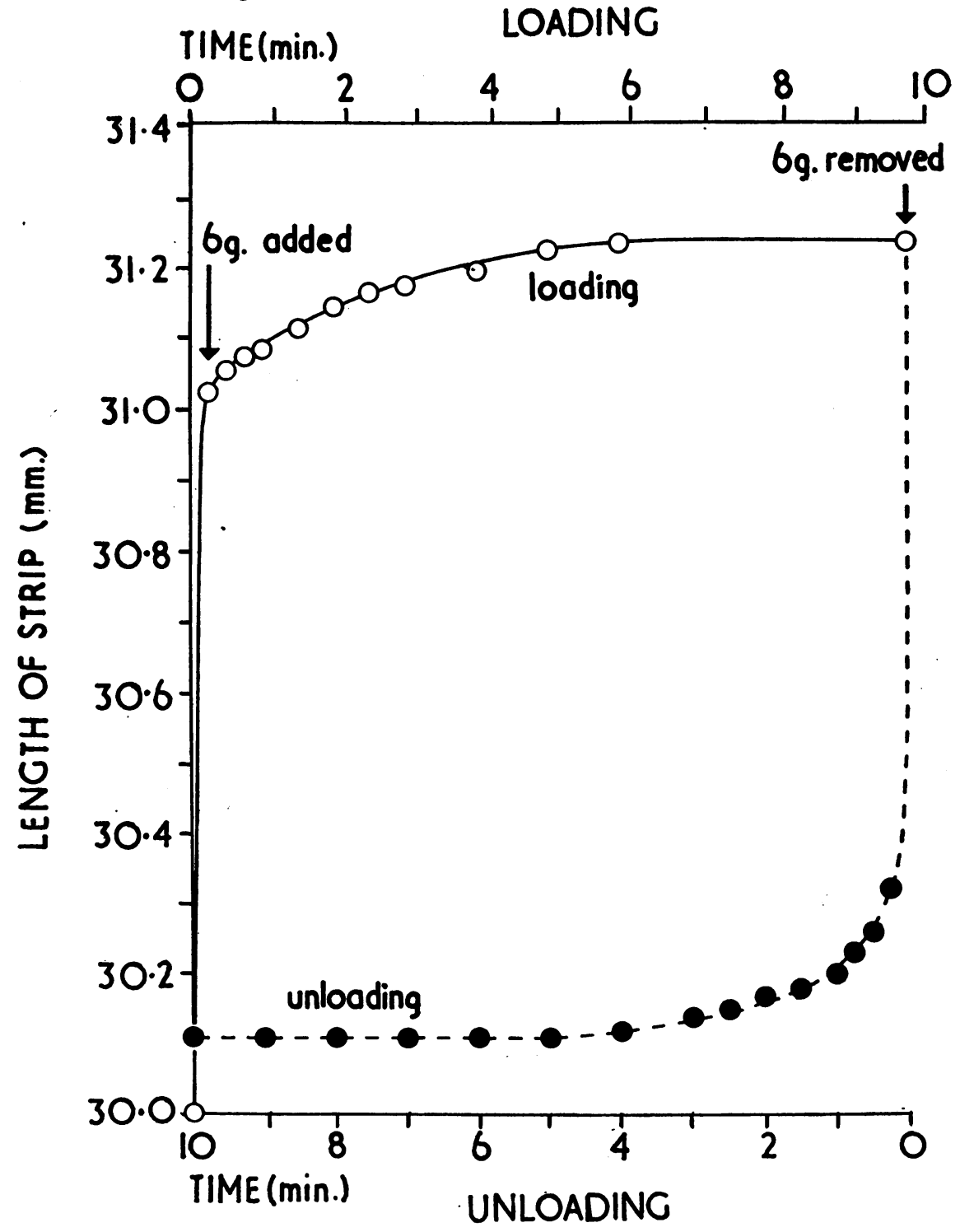

FIG. 3.-Rate of change in length of a strip of sclera after addition and removal of a 6-g. weight. 
The elongation for a given increase in tension became progressively less as the total tension increased up to approximately $15 \mathrm{~g} . \mathrm{wt} / \mathrm{cm}$., after which the elongation was nearly proportional to the increase in tension up to the maximum used-i.e. $60 \mathrm{~g} . \mathrm{wt} / \mathrm{cm}$.

In Fig. 4 the unbroken line represents the elongation of a strip of sclera as the tension was increased. The broken line represents the behaviour of the same strip as the tension was reduced. As can be seen in this example, there were smaller changes in the length of the strip for the same changes in tension during the removal of the weights than during the addition of the weights.

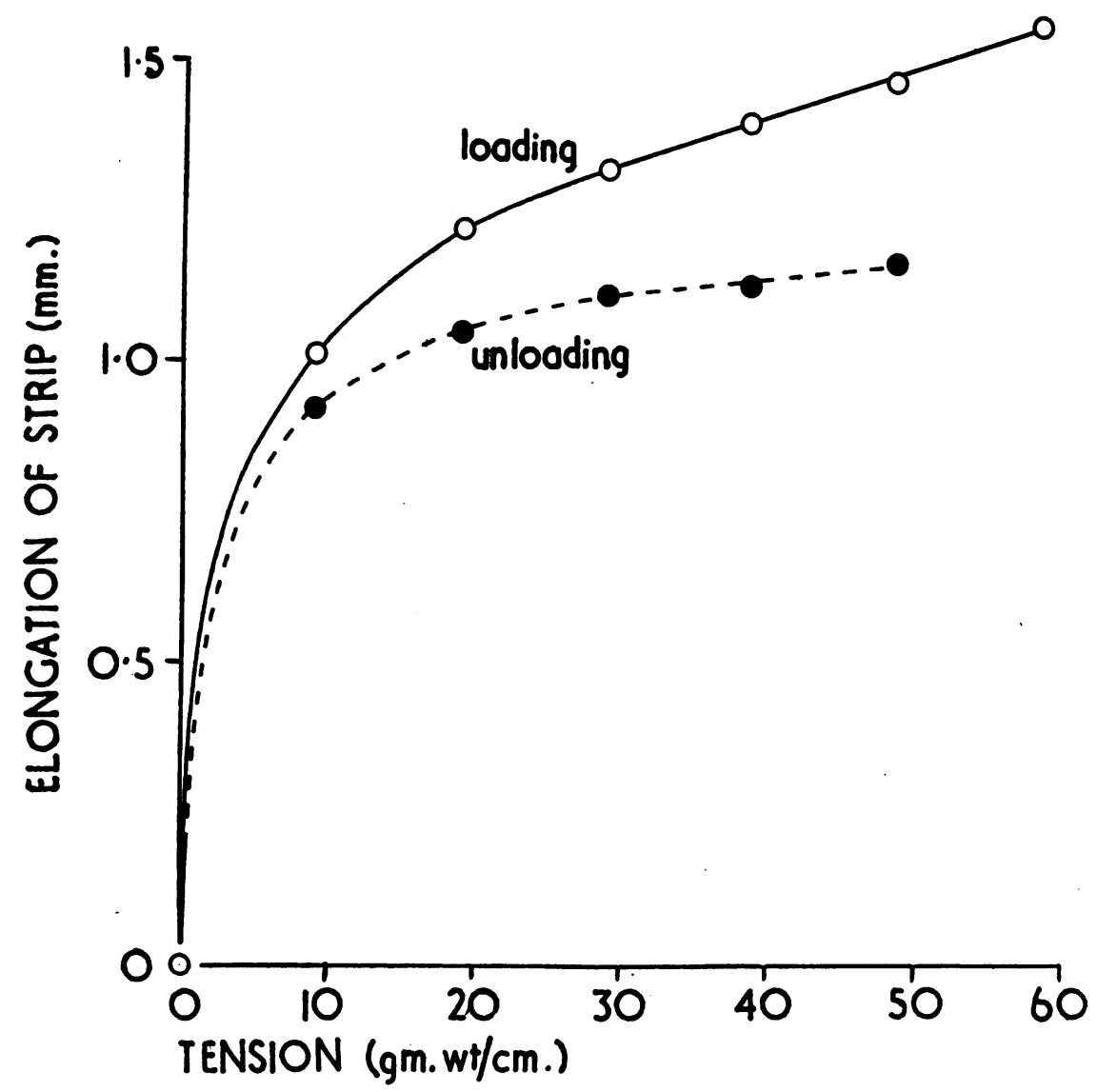

Fig. 4.-Change in length of a strip of sclera with increasing and decreasing tensions.

A convenient way of comparing strips from different eyes is to express the percentage increase in the length of the strip for an increase in tension of from 10-15 g.wt $/ \mathrm{cm}$. This figure was chosen as it corresponds approximately to a change in intra-ocular pressure of from 20 to $30 \mathrm{~cm}$. saline. The results from eight scleral strips (six equatorial and two meridional) and two 
corneal strips are shown in the Table (below). The figures show a fairly wide variation between individual eyes, the figures during loading always being higher than the figures during unloading. No significant difference was apparent between the equatorial and meridional scleral strips nor between the cornea and sclera, although the existence of such differences might be revealed in a larger series of experiments.

TABLE

EXTENSIBILITY OF STRIPS OF SCLERA AND CORNEA

\begin{tabular}{|c|c|c|c|c|}
\hline & \multicolumn{2}{|l|}{ Strips } & \multicolumn{2}{|c|}{$\begin{array}{l}\text { Percentage Change in Length of Strips for } \\
\text { Change in Tension from } 10 \text { to } 15 \mathrm{~g} \cdot \mathrm{wt} / \mathrm{cm}\end{array}$} \\
\hline & & & Loading & Unloading \\
\hline \multirow{8}{*}{ Sclera } & \multirow[t]{6}{*}{ (a) Equatorial } & 1 & $0 \cdot 37$ & 0.23 \\
\hline & & 2 & 0.43 & 0.25 \\
\hline & & 3 & 0.93 & $0 \cdot 10$ \\
\hline & & 4 & 0.52 & 0.22 \\
\hline & & 5 & 0.94 & 0.38 \\
\hline & & 6 & 0.48 & 0.33 \\
\hline & \multirow[t]{2}{*}{ (b) Meridional } & 1 & $0 \cdot 80$ & 0.52 \\
\hline & & 2 & $0 \cdot 38$ & 0.29 \\
\hline \multirow{2}{*}{\multicolumn{2}{|c|}{ Cornea }} & 1 & 0.92 & $0: 42$ \\
\hline & & 2 & 0.67 & 0.40 \\
\hline
\end{tabular}

\section{Discussion}

For the purpose of comparing these results obtained from strips of sclera and cornea with those obtained by distension of the intact eye, the latter are most conveniently expressed as in Fig. 5 (opposite).

Here the change in intra-ocular pressure divided by the corresponding change in volume of the eye $\left(\frac{\Delta P}{\Delta V}\right)$ has been plotted against the intra-ocular pressure at which each value of $\frac{\Delta P}{\Delta V}$ was obtained. This graph shows that, as the intra-ocular pressure rises, the increase in intra-ocular pressure induced by the same change in volume of the eye becomes greater. This means that the eye becomes less distensible at higher pressures, and, if this is due to the physical properties of the sclera, one would expect isolated strips of sclera to become less extensible as the total tension in them is increased. Our results agree with this expectation for tensions up to 


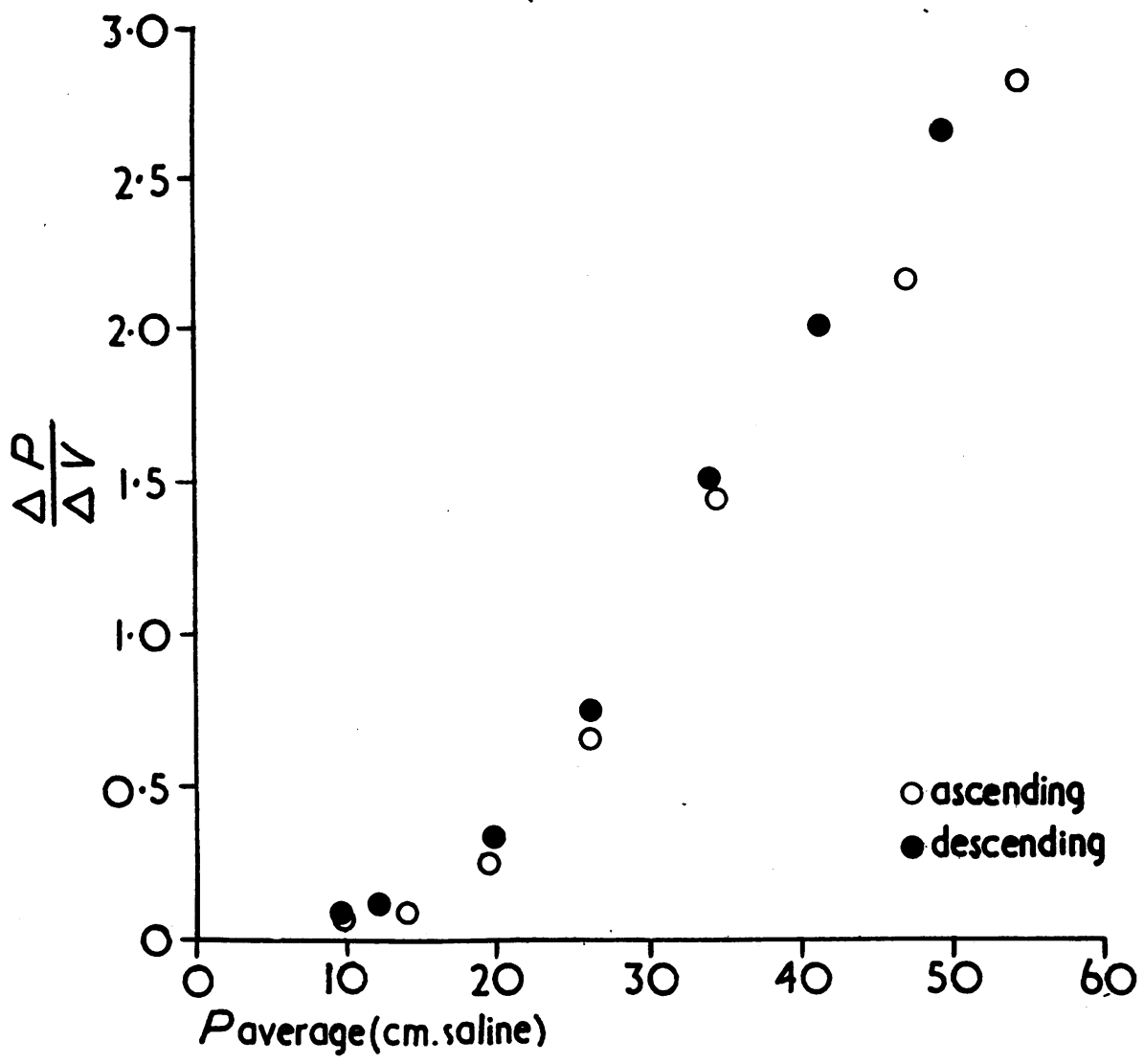
FIG. 5.-Change in pressure per unit change in volume in the eye $\left(\frac{\Delta P}{\Delta V}\right)$ at various intra-ocular
pressures.

20 g.wt./cm., but above this level the extensibility tended to become more constant.

In the experiments on distension of the eye (Perkins and Gloster, 1957), it was found that, when measurements were made after the eye had been subjected to a raised intra-ocular pressure (solid circles in Fig. 5), larger changes of pressure resulted from a constant change of volume than in the undistended eye. In the present series of experiments, the elongation for a given change of tension was less during the removal of the weights than during the addition of the weights (Table). As in the previous comparison, there is some measure of agreement between the results of the two types of experiment.

There are certain factors which make it unlikely that the two sets of data would agree in greater detail. For example, during distension of an intact eye, the cornea and sclera can be considered to stretch in two directions at right angles to one another and to decrease in thickness. During the 
extension of an isolated strip, on the other hand, the sclera increases in length in one direction only and decreases in both width and thickness. Also it may be significant that, in the experiments on extensibility, the strip never returned to its original length after the weights were removed, suggesting that a structural change in the arrangement of the individual fibres may have occurred in this type of experiment. It is not, therefore, justifiable to draw too close an analogy between the behaviour of an intact eye during distension and that of an isolated strip of sclera or cornea.

\section{Summary}

(1) The extensibility of isolated strips of cornea and sclera from rabbit eyes was measured.

(2) It was found that, when the tension in the strip was increased, elongation was rapid at first but became progressively slower until stretching was completed.

(3) The elongation of the strip for a given increase in tension decreased as the initial tension increased, up to a value of approximately $15 \mathrm{~g} . \mathrm{wt} . / \mathrm{cm}$.

(4) The results are discussed in relation to previous work on the distensibility of the intact eye.

\section{REFERENCES}

Friedenwald, J. S. (1937). Amer. J. Ophthal., 20, 985.

ISCHREYT, G. (1899). v. Graefes Arch. Ophthal., 48, 384.

Perkins, E. S., and Gloster, J. (1957). Brit. J. Ophthal., 41, 93.

SCHELSKE, R. (1864). v. Graefes Arch. Ophthal., 10, pt 2, p. 1.

WeBER, A. (1877). Ibid., 23, pt 1, p. 1. 